Historic, Archive Document

Do not assume content reflects current scientific knowledge, policies, or practices. 

62.17

SOUTIR FLORIDA

CITRUS NURS區苜四S

JOSIAH YARN, Proprietor

BRADENTOWN, 沉A。

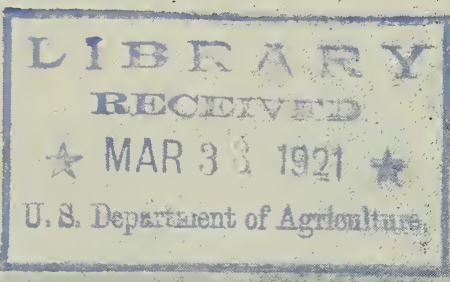

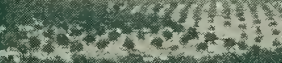

POINTERS

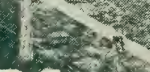

To

SUCCESS 



\section{South Florida}

Citrus Nurseries

Josiah Varn, Proprietor

BRADENTOWN, FLORIDA

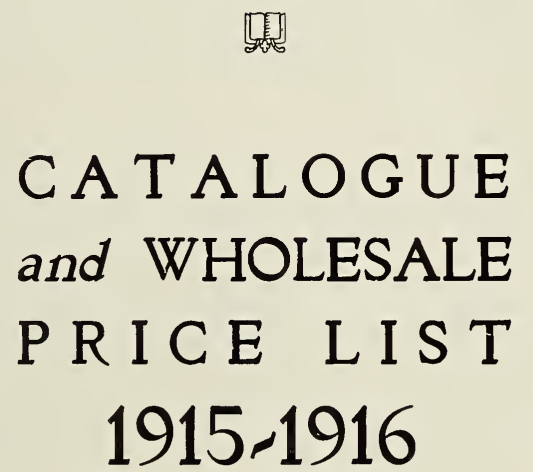

CONTAINING POINTERS

TO SUCCESS 


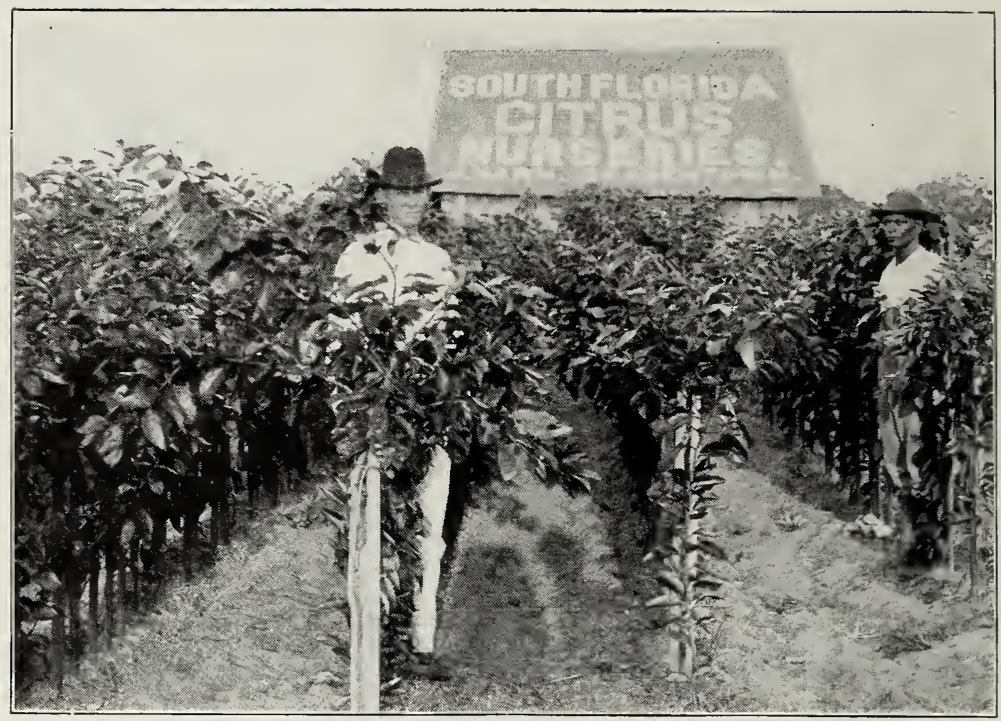

\section{POINTERS TO SUCCESS}

\section{Preparation of Land and Tree Hills}

Remembering that a citrus tree is, in most respects, essentially the same as other hardwood trees, and considering a practical application of soil chemistry to the lands of Florida-always testing theory by actual practice, we deduce the following:

First, that one of the principal differences between the typical citrus land, such as produced the wild groves of Florida and the various kinds of land on which we are today making groves, is the amount of lime salts in the first and the absence of lime salts in the latter.

Second, that wherever acidity of soil exists, the acid is a positive resource if we will simply supply the necessary lime to neutralize the acid, thus making a lime salt.

Third, that in order to effect the chemical change necessary in the soil, after the lime is mixed, finely crushed limestone requires four to six weeks, hydrated lime or air slacked lime requires two to four weeks and good hardwood ashes require ten to twenty days.

Fourth, that wherever sufficient time can be had the crushed limestone 


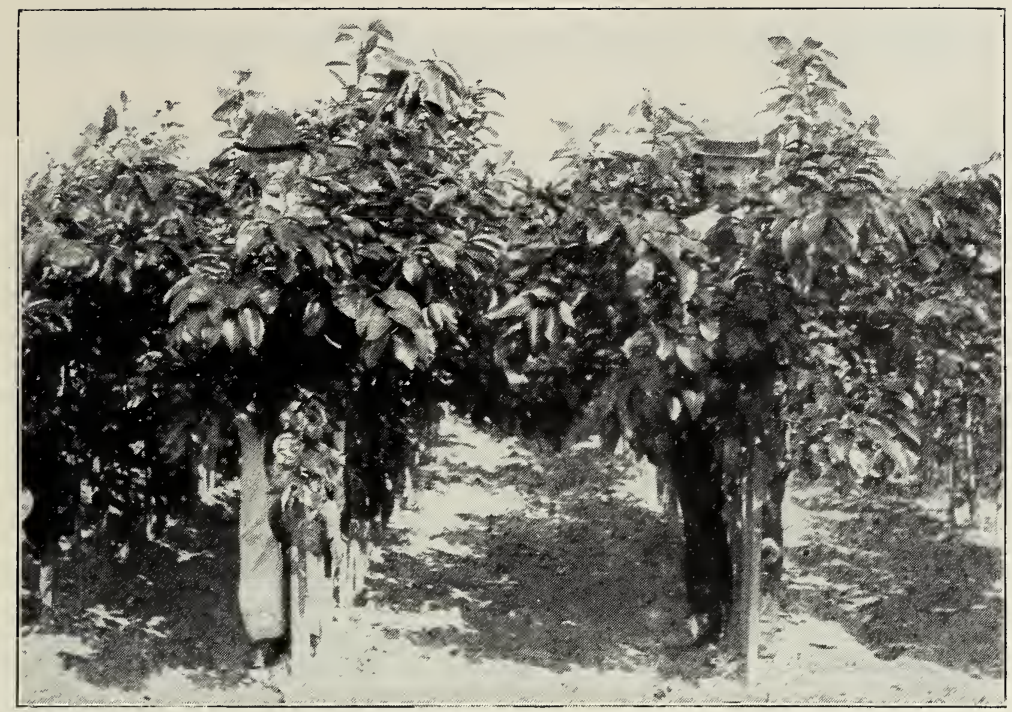

is far more economical to apply both to the tree hill and the entire body of the land.

Fifth, that to thoroughly sweeten the soil in the first effort and thus produce healthy bearing trees in the minimum time, much more lime must be used than is customary, the amount, of course, depending upon the degree of acidity of the soil.

These are all facts that can be abundantly demonstrated not only in our own groves and nurseries in Manatee County, but in many other groves in Manatee County.

\section{Distance Between Trees}

With a view to the maximum profit, so far as it is effected by distance, we must not place seedling oranges and budded oranges in the same class, nor seedling grapefruit and budded grapefruit in the same class, nor classify oranges with grapefruit, for the following reasons:

Seedling trees in both cases being heavier wood producers and lighter fruit producers require much more space than budded trees.

Also, oranges in all cases bear heaviest on the outside of the tree; while grapefruit, if of the best strains and varieties, bear mostly on the inside.

Remembering that the most prolific and also the most profitable grove 


\section{¿ SOUTH FLORIDA CITRUS NURSERIES ¿}

in the world, per acre, is planted two hundred trees per acre and also combining economy of culture, immunity from fungus diseases, and the advantages of a well shaded trunk and root, we strongly recommend that grapefruit be planted more closely than oranges.

Our practice on well irrigated land is, for grapefruit, $14 \times 24$ feet; for oranges, $20 \times 25$ feet.

Where land is not irrigated, increase these dimensions about one-third.

\section{Stocks-Their Nature and Adaptability}

In the commercial groves of South Florida, where citrus fruits are profitable and are grown for profit, experience has caused the leading growers to discard absolutely all stocks except the lemon stock, the grapefruit seedling stock and the sour or native orange stock.

In order to fully describe these from all angles we rate them as follows by numbers:

Grapefruit Sour
Lemon Seedling Orange

1 Rapidity of growth ......................... 1 2 3

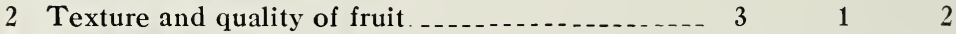

3 Prolificness ............................... 1132

4 Retention of fruit and juice ................... 3 . 321

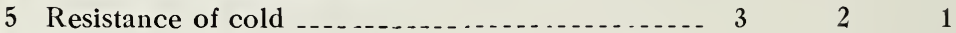

6 Resistance of root disease $\ldots \ldots \ldots \ldots$. .

7 Resistance of fungus disease .................. 3212

8 Adaptability to thirsty light soil ................ 1133

9 Adaptability to heavy hammock, and reclaimed land with clay subsoil..................... $3 \quad 2 \quad 1$

In conclusion, we strongly advise that the root be adapted to the soil, and then carry out your plans for early or late fruit as suggested by 4 above.

\section{Varieties of Grapefruit}

We confine ourselves strictly to those varieties that have given the best results during the past twenty years and which have made the market for grapefruit what it is today, and which are keeping it ahead of all competitors in the whole world.

Since the grapefruit is so very prolific, the best fruit almost invariably is that produced on the inside of the tree, and singly on the stem, also that the sizes demanded in the market range from 64 to 80 per box, it is imperative that these qualities be sought after in the propagation of trees. About ten years ago with these facts in view we sought out the very best 
strains of the several varieties of grapefruit and oranges, obtained buds from bearing trees with the fruit thereon, even at great expense, and we have followed up closely this method, selecting budwood always from specially selected fruiting trees of the best strains. By this method of propagation we are producing trees that are very prolific; true to name and of the very best quality of fruit. WE ARE NOT SELLING VARIETIES OF UNKNOWN VALUE AT FANCY PRICES. THIS GAME HAS BEEN OVERWORKED LONG AGO.

Improved Walter Grapefruit.-Very flat at both ends; bears singly on the stem to a remarkable degree, bears almost entirely on the inside of the tree; thin peel, medium bitter, size 64 to 80 , season October to August; extra good flavor; strong vigorous grower, heavy foliage. Average seediness. NOTHING LATER and NOTHING BETTER. This variety has done more to make a market for Florida grapefruit and to make grapefruit culture a grand financial success than any other variety. Practically thornless, as a result of careful propagation.

Marsh Seedless Grapefruit.-This, first seedless grapefruit ever introduced in Florida, has made good in every respect. Good inside bearer, very prolific, quite flat, but not so much so at the stem end as the Walter; very largely singly on the stem. Sizes 64 to 96 . Season October to June; seeds 4 to 6 ; slightly more bitter than Walter or Pernambuco; good strong grower; thin peel, fine texture, and commands fancy prices. Practically thornless.

Pernambuco Grapefruit.-Good inside bearer; singly on the stem; finely shaped, but not so flat at stem end as Walter. Thin peel, very prolific; size 48 to 72 . The favorite with many successful growers.

\section{Commercial Oranges}

Valencia Late.-This variety of orange, and good grapefruit constitute, in our judgment, the "trump cards" in Florida commercial citrus culture. The Valencia Late, according to the best authorities, was bred up from the Hart's Tardiff, in California, and as we now have it, it certainly fills the gap between the real season of the Florida seedling and California Navel on one hand and the Valencia Late of California on the other. Its true season is May to July. Since it is the most regular bearer of all the citrus family-our trees have borne bumper crops in succession for four yearsit is economy to remove the fruit in June to make room on the tree for the new crop.

If it is desired to keep the fruit later, then place it in cold storage. We know the history of a car of Florida Valencias stored in Philadelphia in May, 1912, that were used in retail trade all summer at $\$ 1.00$ per dozen and the last fruit was sold on Oct. 1, 1912, averaging less than 5 per cent decay. 


\section{¿ SOUTH FLORIDA CITRUS NURSERIES :C}

Don't require your trees to carry fruit beyond the natural limit of its season. It is over-working the tree and over-working never pays.

It fills all the demands that can reasonably be expected of any late orange, and is as near perfect in every respect as skill can hope to produce.

It is the money maker of the orange family.

Lue Gim Gong.-A very fine late orange, and carries great promise of success. Its propagator claims it will hang on the tree in good condition a year or more after maturity.

Hart's Tardiff:-The standard late orange of Florida for 35 years, has few equals in all the world and no superior except the Valencia Late, and, perhaps, the Lue Gim Gong.

Pineapple.- The best midseason orange; finest flavored of all in its season, November to April; a fine bearer, fine texture, strong grower and best money maker next to the late oranges.

Parson Brown. - The best early orange for Florida. It has proven a great success in the upper counties of the orange belt of Florida. Season October to January. The strain known as the Carney Parson Brown is the best bearer and best adapted to South Florida. We confine ourselves to this strain exclusively for early oranges.

Dancy Tangerine. - The standard for Florida. Good bearer, fine flavor, beautiful in texture, size and shape. Best adapted to high sandy loam. Don't plant tangerines on heavy hammock.

Limes.-The lime of commerce is generally called the Mexican or Cuban. We have on the West Coast of Manatee County a strain that is very prolific, easy to produce, well adapted to most soils, with the true lime flavor and but two to four seeds, continuous in maturing from June to October. We believe that as a commercial lime it cannot be excelled. We propagate the seedling trees for the keys, bay front lands and very light, sandy soils, but bud on the lemon stock for all other demands.

\section{Personal}

Born and reared in one of the oldest and best groves of Polk County, and educated especially along horticultural and agricultural lines, we have been in the citrus nursery and grove business from boyhood and have been producing fine nursery and grove trees for 34 years. We have no occasion for apology, but will compare records for success and square dealing with any one, and our groves, over fifty acres, and production of trees for next season, about sixty thousand, speak for themselves. If possible, come and see them. Seeing the great necessity for better marketing facilitics we gave practically one entire year's work, without pay, in organizing and managing the Florida Orange Growers' Company, which paved the way 
for, and was reorganized into the present Florida Citrus Exchange. References, the Bradentown Bank \& Trust Co., the Manatee County Sub-Exchange, Bradentown, Fla.

\section{Production}

We are very fortunate in having our nurseries located on sandy loam soil, well drained, and also well irrigated by our fine flowing wells, in well protected localities where trees have never been injured by frost. We make them grow ten months in the year and give them two months' rest, thus producing trees perfect in every respect and with the very maximum of feeding rootlets. Our entire system of culture is promotive of a perfect top with a perfect root. No stunted trees in ours. Our trees are stake trained and branched at three feet high-thus forming the top at the right height, in the right way, and at the right time, and then we head back the limbs so as to preserve the top as a part of the tree and not compel the purchaser to form and develop a top himself, above and out of the canelike trunk as usually grown and shipped.

\section{Our Grading System}

Since our orange and grapefruit trees are branched at three feet, with but very slight variation, we grade both by height and caliper of the bud. The root varies in ages from two to three years old when it is budded, so the age of root will be two to three years plus the age of the bud. All trees well branched, if half inch or above in caliper of bud.

\section{PRICE LIST}

(For Orders Booked before December 1st)

\section{Oranges, Grapefruit, Seedling Limes}

\begin{tabular}{|c|c|c|c|}
\hline Height & Caliper of Bud & Age of Bud & Per 1000 \\
\hline 2 to $3 \mathrm{ft}$. & $\frac{8}{8}$ to $\frac{1}{2}$ in... & 8 to 10 mos. & $\$ 280.00$ \\
\hline 3 to $4 \mathrm{ft}$. & $\frac{1}{2}$ to $\frac{5}{8} \mathrm{in}$. & 10 to 12 mos. $\ldots$ & 400.00 \\
\hline 4 to & $\frac{5}{8}$ to $\frac{3}{4} \mathrm{in}$. & 12 to 15 mos. & 550.00 \\
\hline 5 to & $\frac{3}{4}$ to 1 in & 15 to 24 mos. & 750.00 \\
\hline 6 to & 1 to $1 \frac{1}{4}$ ir & 24 to 30 mos. & 900.00 \\
\hline
\end{tabular}

\section{Tangerines and Budded Limes}

(By Height Only)

Height

3 to $4 \mathrm{ft}$.

4 to $5 \mathrm{ft}$
Age of Bud

10 to $15 \mathrm{mos}$

12 to 24 mos.
Per 100

$\$ 40.00$

60.00
Per 1000

$\$ 380.00$

550.00

Lots of 50 trees at the 100 -rate, and 500 at the 1000 -rate. 


\section{¿ SOUTH FLORIDA CITRUS NURSERIES ¿}

The above prices we believe are in accord with our rule, viz.: "AS GOOD AS THE BEST AND AS CHEAP AS THE CHEAPEST."

We are booking orders rapidly and some lines of our stock are running low already. Therefore, ORDER IMMEDIATELY, and let us reserve your trees in the nursery until setting time, viz.: December 1 to February 15 , on the lower West Coast. You have all to gain and nothing to lose by quick action.

Terms.-The same as customary.

State your wants, and if orders are large enough we will give you a discount. Address,

JOSIAH VARN, Prop., BRADENTOWN, FLA. 


\section{SOUTM TSORIDAA}

\section{CITRUS NURSIRUIS}

JOSIAH VARN, Proprietor BRADENTOWN, FLA

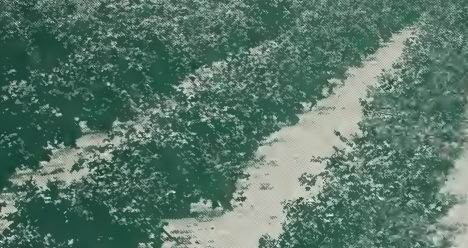

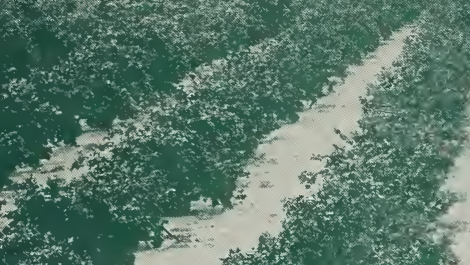

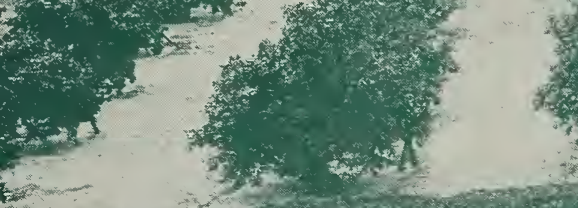

